\title{
Comparative studies on phenolic profiles, antioxidant capacities and carotenoid contents of red goji berry (Lycium barbarum) and black goji berry (Lycium ruthenicum)
}

Tahidul Islam ${ }^{1}$, Xiaoming Yu', Tanvir Singh Badwal'² and Baojun Xu ${ }^{1 *}$

\begin{abstract}
Background: The study on phytochemical difference between red and black goji berry is limited.

Methods: Antioxidant activities and phenolic profiles in terms of total phenol content, total flavonoid contents, condensed tannin content, monomeric anthocyanin content, and total carotenoid content of red goji berry (Lycium barbarum) and black goji berry (L. ruthenicum) were compared using colorimetric assays.

Results: All goji berries were rich in phenolics. Black goji berry had the highest phenolic, condensed tannin content and monomeric anthocyanin content. Black goji berry samples possessed higher antioxidant capacities than red goji berry, while the red goji berry had the highest carotenoid content. Goji berries exhibited a positive linear correlation between phenolic compounds and antioxidant capacities. The average value of carotenoid content in red goji berry was $233.04 \mu \mathrm{g} / \mathrm{g}$.
\end{abstract}

Conclusion: The phenolics and antioxidant capacities are much higher in black goji berry than red goji berry, while carotenoid content is much higher in red than black.

Keywords: Goji berry, Antioxidant, Phenolics, Carotenoids, Lycium ruthenicum

\section{Background}

Natural products, in the form of pure compounds or extracts with antioxidant activity, may help the endogenous defense system of the body [1]. Antioxidants obtained through diet are taking on major significance as possible protector agents to diminish oxidative damage. As carcinogenic properties have been reported for some synthetic antioxidants, recent research on the potential applications of natural antioxidants from natural food products, for stabilizing foods against oxidation, have received much attention [2]. Antioxidant supplements or antioxidant containing foods may be used to help the human body to reduce oxidative damage or to

\footnotetext{
${ }^{*}$ Correspondence: baojunxu@uic.edu.hk

${ }^{1}$ Food Science and Technology Program, Beijing Normal University-Hong Kong Baptist University United International College, 28, Jinfeng Road, Tangjiawan, Zhuhai 519085, Guangdong, China

Full list of author information is available at the end of the article
}

protect food quality by preventing oxidative deterioration [3]. The antioxidants contained in foods, especially vegetables, are phenolic compounds (phenolic acids and flavonoids), carotenoids, tocopherol and ascorbic acid [3]. These compounds are important protective agents for human health [4]. Goji berry is a typical example that might be used as nutraceuticals or directly eaten in the diet to maintain good health [5].

Chinese traditional medicinal food goji berry is used for its anti-aging properties, tranquilizing and thirst quenching effects, as well as its ability to increase stamina. The benefits include preventing conditions such as diabetes, hyperlipidemia, cancer, hepatitis, immune disorders, thrombosis, and male infertility [6-8]. There are several clinical and experimental reports showing an anti-diabetic effect of Lycium barbarum as it is wellknown in traditional Chinese herbal medicine for diabetes. $L$. barbarum reduced oxidation in patients with 
retinopathy [9]. The presence of various functional components like polysaccharides, flavonoids and carotenoids in $L$. barbarum fruits is believed to be responsible for these effects $[7,10,11]$. A group of lipid-soluble compounds is carotenoids with color ranging from yellow to red, have been shown to be present in large quantity in fruits of L. barbarum [12]. Several physiological studies have focused on polysaccharides and carotenoids; however, flavonoids have been less investigated, especially for their antioxidant activity $[13,14] . L$. barbarum fruit and polysaccharide from it possess a range of biological activities, including anti-aging, neuroprotection, increased metabolism, glucose control in diabetics, glaucoma, anti-oxidant properties, immunomodulation, anti-tumor activity and cytoprotection $[13,15,16]$; Lycium ruthenicum fruit contains abundant anthocyanins and a highly branched arabinogalactan protein [17, 18]. Goji berries contain carotenoids (beta-carotene, lutein, lycopene, zeaxanthin, zeaxanthin dipalmitate), polysaccharides (comprising 30\% of the pulp), vitamins (ascorbic acid glucopyranosyl ascorbic acid, and tocopherol), fatty acids, betaine, and peptidoglycans [19-22].

As compared to the red goji berry, the study on black goji berry (L. ruthenicum) is limited. It is necessary to compare the differences between red and black goji berry in terms of phytochemical and antioxidant capacities. The objectives of the present study aim at assessing the phenolic profile, antioxidant properties and carotenoid content of red goji berry (L. barbarum) and black goji berry (L. ruthenicum), and provide scientific insight into the phenolic and antioxidant functions of both red and black goji berry to consumers and nutraceutical industry.

\section{Methods}

\section{Goji berry samples}

Dried fruits of goji berry (L. barbarum and L. ruthenicum) belonging to the family of Solanaceae, were produced from Ningxia Autonomous Region and Qinghai
Province, China. The sample information is listed in Table 1, and the morphological features based on place of origin of dried goji berry fruits are presented in Fig. 1.

\section{Chemicals and reagents}

2,2'-Azino-bis(3-ethylbenzothiazoline-6-sulfonic acid) (ABTS), Folin-Ciocalteu reagent, 2-diphenyl-1-picryhydrazyl (DPPH), potassium persulphate $\left(\mathrm{K}_{2} \mathrm{~S}_{2} \mathrm{O}_{8}\right)$, sodium carbonate, gallic acid, sodium hydroxide, sodium nitrite, sodium acetate, acetic acid, hydrogen chloride, 2,4,6-tri(2pyridyl)-s-triazine (TPTZ), ferric chloride, ferrous sulfate, aluminum chloride hexahydrate, $(+)$-catechin, 6-hydroxy2,5,7,8-tetramethylchroman-2-carboxylic acid (Trolox), acetone, phosphate buffer saline (PBS), hydrogen chloride $(\mathrm{HCl})$, potassium chloride $(\mathrm{KCl})$, vanillin, methanol, butylated hydroxytoluene (BHT), potassium hydroxide, $n$-hexane was obtained from Sigma-Aldrich Co. (Shanghai, China). Absolute ethanol was from Tianjin Fuyu Fine Chemical Co., Ltd. (Tianjin, China). Other chemical reagents were supplied by Tianjin Damao Chemical Reagent Co., Ltd. (Tianjin, China). All chemicals were of analytical grade unless specially mentioned.

\section{Extraction of goji berry sample}

The goji berry sample extraction procedure was described by Xu and Chang [23]. Briefly, pestle and mortar were used to grind dried goji berry fruits, $.5 \mathrm{~g}$ of dry ground goji berry samples (in triplicate) were extracted two times with $5 \mathrm{~mL}$ extraction solvent of acetone/water/ acetic acid (70:29.5:5) each time. Extracts were shaken for $3 \mathrm{~h}$ at $300 \mathrm{rpm}$ using an orbital shaker, then samples extracted were placed in the dark for $12 \mathrm{~h}$. After $12 \mathrm{~h}$ the extract samples were centrifuged at $3000 \mathrm{rpm}$ for $10 \mathrm{~min}$. The supernatants were stored at $4{ }^{\circ} \mathrm{C}$ in dark for determination of total phenolic content (TPC), total flavonoid content (TFC), total condensed tannin content (CTC), monomeric anthocyanin content (MAC), and antioxidant activities.

\section{Table 1 Sample information of goji berry collected}

\begin{tabular}{|c|c|c|c|}
\hline Sample ID & Common name & Scientific name & Place of origin \\
\hline R1 & Red goji berry & Lycium barbarum & $\begin{array}{l}\text { LiuYing Village, Xinbao Town, Zhongning County, Zhongwei City, NingXia Hui Autonomous } \\
\text { Prefecture }\end{array}$ \\
\hline $\mathrm{R} 2$ & Red goji berry & Lycium barbarum & Xinxiaoxian in Xixia District, Yinchuan City, NingXia Hui Autonomous Prefecture \\
\hline R3 & Red goji berry & Lycium barbarum & $\begin{array}{l}\text { Huangbin Village, Ningan Town, Zhongning County, Zhongwei City, NingXia Hui Autonomous } \\
\text { Prefecture }\end{array}$ \\
\hline R4 & Red goji berry & Lycium barbarum & Helan county, Yinchuan City, NingXia Hui Autonomous Prefecture \\
\hline B1 & Black goji berry & Lycium ruthenicum & The second battalion of Nuomuhong Farm from Qinghai Province \\
\hline B2 & Black goji berry & Lycium ruthenicum & South gate No. 43. Xining City, Qinghai Province \\
\hline B3 & Black goji berry & Lycium ruthenicum & Nuomuhong Farm,Qinghai Province \\
\hline B4 & Black goji berry & Lycium ruthenicum & The first battalion of Nuomuhong Farm, Qinghai Province \\
\hline
\end{tabular}



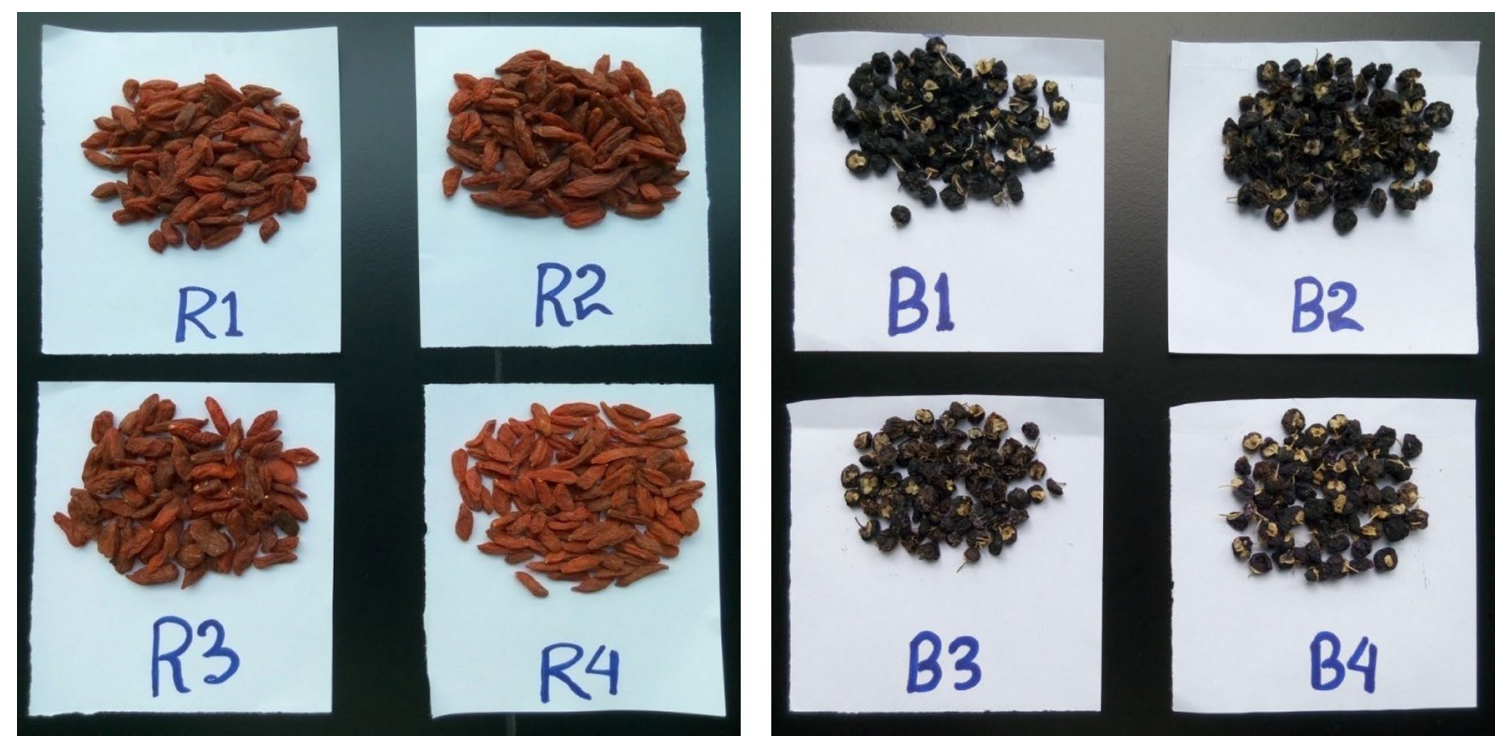

Fig. 1 Pictures of red goji berry (L. barbarum) and black goji berry (L. ruthenicum) fruits

\section{Determination of TPC}

Total phenolic content was determined using a colorimetric method as described by Singleton et al. [24, 25] The absorbance was measured by a UV-visible spectrophotometer (TU-1901) at $765 \mathrm{~nm}$. The TPC was expressed as gallic acid equivalents (mg GAE/g sample) in accordance to standard calibration curve of gallic acid with linear range of $50-1000 \mu \mathrm{g} / \mathrm{mL}\left(\mathrm{R}^{2}>.99\right)$.

\section{Determination of TFC}

Total flavonoids content was determined using a colorimetric method as described by Heimler et al. [26]. The absorbance was measured by a UV-visible spectrophotometer (TU-1901) at $510 \mathrm{~nm}$. The TFC was expressed as catechin equivalents (mg CAE/g sample) in accordance to standard calibration curve of catechin with linear range from 10 to $1000 \mu \mathrm{g} / \mathrm{mL}\left(\mathrm{R}^{2}>.99\right)$.

\section{Determination of CTC}

Condensed tannin content was determined using a colorimetric method as described by Broadhurst and Jones [27]. The absorbance was measured by a UV-visible spectrophotometer (TU-1901) at $500 \mathrm{~nm}$. The CTC was expressed as catechin equivalents (mg CAE/g sample) in accordance to standard calibration curve of catechin with linear range of $50-1000 \mu \mathrm{g} / \mathrm{mL}\left(\mathrm{R}^{2}>.99\right)$.

\section{Determination of MAC}

Monomeric anthocyanin content monomeric anthocyanin content was based on a $\mathrm{pH}$ differential method described previously by Lee et al. [28] with no modifications. The MAC was calculated in the form of $\mathrm{w} / \mathrm{w} \%$ of total anthocyanin in the samples using the molecular weight for cyanidin-3-glucoside (449.2 g/ mol) and its extinction coefficient $(26,900 \mathrm{~L} \mathrm{~cm} / \mathrm{mol})$. MAC was expressed as cyanidin-3-glucoside equivalents because of its historical usage for similar assays and its wide commercial availability [28].

\section{Determination of DPPH free radical scavenging capacity}

$\mathrm{DPPH}$ was determined using a colorimetric method as described by Chen and Ho [29]. The absorbance was measured by a UV-visible spectrophotometer (TU-1901) at $517 \mathrm{~nm}$ using extraction solvent to replace the sample as blank. The DPPH was expressed as Trolox equivalents ( $\mu \mathrm{mol} \mathrm{TE} / \mathrm{g}$ sample) according to standard calibration curve of Trolox with a linear range from 100 to $750 \mu \mathrm{M}\left(\mathrm{R}^{2}>.99\right)$.

\section{Determination of Ferric reducing antioxidant capacity}

Ferric reducing antioxidant capacity (FRAP) was determined using a colorimetric method as described by Benzie and Strain [30]. The absorbance was measured by a UV-visible spectrophotometer (TU-1901) at $593 \mathrm{~nm}$ using extraction solvent to replace the sample as blank. The FRAP value was expressed as mmol of $\mathrm{Fe}^{2+}$ equivalents per $100 \mathrm{~g}$ of sample (mmol Fe${ }^{2+} \mathrm{E} / 100 \mathrm{~g}$ sample) according to standard calibration curve of $\mathrm{Fe}^{2+}$ with linear range from 50 to $1000 \mu \mathrm{M}\left(\mathrm{R}^{2}>.99\right)$.

\section{Determination of $A B T S$ radical scavenging assay}

ABTS was determined using a colorimetric method as described by Brown and Miller [31], and Re et al. [32]. 
The absorbance was measured by the UV-visible spectrophotometer (TU-1901) at $734 \mathrm{~nm}$ after $6 \mathrm{~min}$ reaction in spectrophotometer set at $30^{\circ} \mathrm{C}$, extraction solvent used as blank. The ABTS value was expressed as Trolox equivalents ( $\mu \mathrm{mol} \mathrm{TE} / \mathrm{g}$ sample) in accordance to standard calibration curve of Trolox with linear range from 50 to $1000 \mu \mathrm{M}\left(\mathrm{R}^{2}>.99\right)$.

\section{Determination of total carotenoid content (TCC)}

TCC was determined using a colorimetric method as described by Sanusi and Adebiyi [33], with slight modifications. Briefly, a $.5 \mathrm{~g}$ goji berry sample in triplicates was extracted with $5 \mathrm{~mL}$ of ethanolic butylated hydroxyl toluene (ethanol/BHT-100:1, v/w) for isolation and the release of carotenoids. Then, it was mixed completely, and placed in a water bath at $85{ }^{\circ} \mathrm{C}$ for $5 \mathrm{~min}$. After that, $.5 \mathrm{~mL}$ of $80 \% \mathrm{KOH}$ was added for saponification and properly vortexed before putting it back to $85{ }^{\circ} \mathrm{C}$ water bath for $10 \mathrm{~min}$. The mixture was cooled down in an ice-water bath and was added to $3 \mathrm{~mL}$ of cold deionized water. Then $n$-hexane $(3 \mathrm{~mL})$ was mixed with the mixture before centrifugation at $7500 \mathrm{rpm}$ for $5 \mathrm{~min}$ for the separation of two layers. The upper layer with yellow was transferred and collected. This procedure was repeated four times until the upper layers became colorless [34]. Therefore, a total of $12 \mathrm{~mL}$ of hexane was put into each centrifuge tube and the final volume of each tube was recorded. The samples were read at the wavelengths of both $450 \mathrm{~nm}$ and $503 \mathrm{~nm}$ against the hexane as the blank [35]. The concentration of total carotenoid in the extract was calculated by following equation: $\mathrm{C}_{\text {carotene }}=4.642 \times \mathrm{A}_{450}-3.091 \times \mathrm{A}_{503}$, where is $C$ concentration of carotenoid expressed in $\mu \mathrm{g} / \mathrm{mL}$, $\mathrm{A}_{450}=$ absorbance value at $450 \mathrm{~nm}$, and $\mathrm{A}_{503}=$ absorbance value at $503 \mathrm{~nm}$ [35]. Finally, the total carotenoid content in dry fruits was expressed in $\mu \mathrm{g} / \mathrm{g}$.

\section{Statistical analysis}

All of the assays were conducted in triplicate extracts and the results were expressed in means \pm standard deviations on the basis of dry weight. The significant differences between mean values of samples were determined by analysis of variance (one-way ANOVA) using LSD significant difference test at a significance level of $p \leq .05$.

\section{Results}

\section{Total phenolic content of goji berry}

The total phenolic contents (expressed in $\mathrm{mg}$ GAE/g) of 8 goji berry samples are presented in Table 2. Black goji berry samples B1, B3, B2 and B4 (9.01, 8.95, 8.08 and $7.26 \mathrm{mg} \mathrm{GAE} / \mathrm{g}$ ) had relatively higher total phenolic content, while the red goji berry samples R3, R2, R1, and R4
Table 2 TPC, TFC, CTC, and MAC of goji berry

\begin{tabular}{llrlr}
\hline $\begin{array}{l}\text { Sample } \\
\text { no. }\end{array}$ & $\begin{array}{l}\text { TPC }(\mathbf{m g} \\
\text { GAE } / \mathbf{g})\end{array}$ & \multicolumn{1}{l}{$\begin{array}{l}\text { TFC }(\mathbf{m g} \\
\text { CAE } / \mathbf{g})\end{array}$} & \multicolumn{1}{l}{$\begin{array}{l}\text { CTC }(\mathbf{m g} \\
\text { CAE } / \mathbf{g})\end{array}$} & MAC $(\mathbf{m g} / \mathbf{g})$ \\
\hline R1 & $3.12 \pm 0.28 \mathrm{e}$ & $2.67 \pm 0.21 \mathrm{C}$ & $1.24 \pm 0.28 \mathrm{e}$ & $.25 \pm 0.98 \mathrm{~d}$ \\
R2 & $2.87 \pm 0.28 \mathrm{e}$ & $2.78 \pm 0.21 \mathrm{C}$ & $1.17 \pm 0.28 \mathrm{e}$ & $.22 \pm 0.98 \mathrm{~d}$ \\
R3 & $2.17 \pm 1.00 \mathrm{f}$ & $2.69 \pm 0.21 \mathrm{C}$ & $1.06 \pm 0.28 \mathrm{e}$ & $.21 \pm 0.98 \mathrm{~d}$ \\
R4 & $4.48 \pm 1.00 \mathrm{~d}$ & $3.16 \pm 0.21 \mathrm{C}$ & $.86 \pm 0.28 \mathrm{e}$ & $.28 \pm 0.98 \mathrm{~d}$ \\
B1 & $9.01 \pm 0.77 \mathrm{a}$ & $10.37 \pm 0.11 \mathrm{~b}$ & $17.36 \pm 1.00 \mathrm{~d}$ & $60.52 \pm 1.00 \mathrm{c}$ \\
B2 & $8.08 \pm 1.00 \mathrm{~b}$ & $12.32 \pm 0.25 \mathrm{a}$ & $23.51 \pm 1.00 \mathrm{a}$ & $82.58 \pm 0.95 \mathrm{a}$ \\
B3 & $8.95 \pm 0.77 \mathrm{a}$ & $11.90 \pm 0.25 \mathrm{a}$ & $22.13 \pm 1.00 \mathrm{~b}$ & $82.41 \pm 0.95 \mathrm{a}$ \\
B4 & $7.26 \pm 1.00 \mathrm{c}$ & $9.77 \pm 0.11 \mathrm{~b}$ & $20.49 \pm 1.00 \mathrm{c}$ & $65.94 \pm 1.00 \mathrm{~b}$ \\
\hline
\end{tabular}

Data were expressed as mean \pm standard deviation $(n=3)$. The data in the

same column marked with different small case letters were significantly $(p<.05)$ different

TPC total phenolic content, TFC total flavonoid content, CTC condensed tannin content, $M A C$ monomeric anthocyanin content

(2.17, 2.87, 3.12, $4.48 \mathrm{mg} \mathrm{GAE/g)} \mathrm{had} \mathrm{relatively} \mathrm{lower}$ phenolic content.

\section{Total flavonoid content of goji berry}

The total flavonoid contents (expressed in $\mathrm{mg} \mathrm{CAE} / \mathrm{g}$ ) of 8 goji berry samples are presented in Table 2 . The relatively higher content of flavonoids was recorded in black goji berry samples B2, B3, B1 and B4 (12.32, 11.90, 10.37 and $9.77 \mathrm{mg} \mathrm{CAE} / \mathrm{g}$ ) while the least content of flavonoids was recorded in red goji berry samples R1, R3, R2 and R4 $(2.67,2.69,2.78$ and $3.16 \mathrm{mg} \mathrm{CAE} / \mathrm{g})$.

\section{Total condensed tannin content of goji berry}

The total condensed tannin contents (expressed in $\mathrm{mg} \mathrm{CAE} / \mathrm{g}$ ) of 8 goji berry samples are presented in Table 2 . The relatively higher content of condensed tannin was recorded in black goji berry samples B2, B3, B4 and $\mathrm{B} 1$ (23.51, 22.13, 20.49 and $17.36 \mathrm{mg} \mathrm{CAE} / \mathrm{g}$ ) while the least content of condensed tannin was recorded in red goji berry samples R4, R3, R2 and R1 (.86, 1.06, 1.17 and $1.24 \mathrm{mg} / \mathrm{g}$ ).

\section{Total monomeric anthocyanin content of goji berry}

The total monomeric anthocyanin contents (expressed in anthocyanins $\mathrm{mg} / \mathrm{g}$ ) of 8 goji berry samples are presented in Table 2. Black goji berry samples B2, B3, B4 and $\mathrm{B} 1(82.58,82.41,65.94$ and $60.52 \mathrm{mg} / \mathrm{g})$ had relatively higher total phenolic content; while the red goji berry samples R3, R2, R1, and R4 (.21, .22, .25 and .28 $\mathrm{mg} / \mathrm{g}$ ) had relatively lower monomeric anthocyanin content.

\section{FRAP radical scavenging activity of goji berry}

FRAP (expressed in mmol $\mathrm{Fe}^{2+} \mathrm{E} / 100 \mathrm{~g}$ ) of 8 goji berry samples is presented in Table 3. The relatively higher 
Table 3 Antioxidant capacities (DPPH, FRAP, ABTS) of goji berry

\begin{tabular}{|c|c|c|c|}
\hline Sample no. & $\begin{array}{l}\operatorname{FRAP}(\mathrm{mmol} \\
\left.\text { of } \mathrm{Fe}^{2+} \mathrm{E} / 100 \mathrm{~g}\right)\end{array}$ & $\begin{array}{l}\text { DPPH }(\mu \mathrm{mol} \\
\mathrm{TE} / \mathrm{g})\end{array}$ & ABTS $(\mu \mathrm{mol} T E / g)$ \\
\hline R1 & $3473.79 \pm 0.09 \mathrm{de}$ & $16.07 \pm 0.35 \mathrm{e}$ & $64.38 \pm 0.58 d$ \\
\hline R2 & $3303.13 \pm 0.09 \mathrm{de}$ & $16.61 \pm 0.09 \mathrm{de}$ & $53.92 \pm 0.58 f$ \\
\hline R3 & $2639.03 \pm 0.28 \mathrm{e}$ & $16.46 \pm 0.09 \mathrm{de}$ & $55.87 \pm 0.08 \mathrm{ef}$ \\
\hline R4 & $4651.04 \pm 0.13 d$ & $17.47 \pm 0.09 c$ & $62.40 \pm 0.58 \mathrm{de}$ \\
\hline B1 & $28957.95 \pm 0.13 c$ & $35.86 \pm 0.74 a$ & $150.51 \pm 0.33 c$ \\
\hline B2 & $33930.79 \pm 1.00 b$ & $35.68 \pm 0.74 a$ & $180.03 \pm 1.00 a$ \\
\hline B3 & $36346.61 \pm 1.00 a$ & $33.30 \pm 0.08 b$ & $167.59 \pm 1.00 b$ \\
\hline B4 & $27821.53 \pm 0.13 c$ & $32.29 \pm 0.08 b$ & $147.00 \pm 0.33 c$ \\
\hline
\end{tabular}

Data were expressed as mean \pm standard deviation $(n=3)$. The data in the same column marked with different small case letters were significantly $(p<.05)$ different

FRAP ferric reducing anti-oxidant capacity, $D P P H$ free radical scavenging capacity, $A B T S$ radical scavenging assay

FRAP were recorded in black goji berry samples B3, B2, B1 and B4 $(36,346.61,33,930.79,28,957.95$ and $27,821.53 \mathrm{mmol} \mathrm{Fe}^{2+} \mathrm{E} / 100 \mathrm{~g}$ ), while the least antioxidant capacities were found in red goji berry samples R3, R2, R1 and R4 (2639.03, 3303.13, 3473.79 and $4651.04 \mathrm{mmol}$ $\left.\mathrm{Fe}^{2+} \mathrm{E} / 100 \mathrm{~g}\right)$.

\section{DPPH free radical scavenging activity of goji berry}

The DPPH free radical scavenging activity (expressed in $\mu \mathrm{mol} \mathrm{TE} / \mathrm{g}$ ) of 8 goji berry samples is presented in Table 3. The relatively higher DPPH scavenging abilities recorded in black goji berry samples B1, B2 B3 and B4 (35.86, 35.68, 33.30 and $32.90 \mu \mathrm{mol} \mathrm{TE} / \mathrm{g}$ ) while the least DPPH scavenging abilities were found in red goji berry samples R1, R3, R2 and R4 (16.07, 16.46, 16.61 and $17.47 \mu \mathrm{mol} \mathrm{TE} / \mathrm{g})$.

\section{ABTS radical scavenging activity of goji berry}

The results of ABTS radical scavenging activity of 8 goji berry samples are presented in Table 3. Black goji berry samples B2, B3, B1 and B4 (180.03, 167.59, 150.51 and $147.00 \mu \mathrm{mol} \mathrm{TE} / \mathrm{g}$ ) exhibited the relatively higher ABTS radical scavenging, while the lowest were found in red goji berry samples R2, R3, R4 and R1 (53.92, 55.87, 62.40 and $64.38 \mu \mathrm{mol} \mathrm{TE} / \mathrm{g})$.

\section{Total carotenoid content of goji berry}

The total carotenoid contents of 8 goji berry samples are presented in Table 4. R1, R3, R4 and R2 (233.08, 224.21, 222.63 and $212.24 \mu \mathrm{g} / \mathrm{g}$ ) had the highest carotenoids while the lowest were found in B4, B1, B2, and B3 (1.51, $1.96,2.77$, and $3.19 \mu \mathrm{g} / \mathrm{g}$ ).
Table 4 Carotenoids (TCC) of goji berry

\begin{tabular}{lr}
\hline Sample no. & \multicolumn{1}{l}{ TCC $(\boldsymbol{\mu g} / \mathbf{g})$} \\
\hline R1 & $233.08 \pm 1.00 \mathrm{a}$ \\
R2 & $212.24 \pm 1.00 \mathrm{c}$ \\
R3 & $224.21 \pm 0.61 \mathrm{~b}$ \\
R4 & $222.63 \pm 0.61 \mathrm{~b}$ \\
B1 & $1.96 \pm 0.62 \mathrm{~d}$ \\
B2 & $2.77 \pm 0.62 \mathrm{~d}$ \\
B3 & $3.19 \pm 0.62 \mathrm{~d}$ \\
B4 & $1.51 \pm 0.62 \mathrm{~d}$
\end{tabular}

Data were expressed as mean \pm standard deviation $(n=3)$. The data in the same column marked with different small case letters were significantly $(p<.05)$ different

TCC total carotenoids content

\section{Discussion}

\section{Phenolic compounds in goji berry}

The highest TPC value was recorded as $9.01 \mathrm{mg} \mathrm{GAE} / \mathrm{g}$ while the lowest TPC value was recorded as $2.17 \mathrm{mg} \mathrm{GAE} / \mathrm{g}$. The average value of 4 black goji berry samples rich in TPC was recorded as $8.33 \mathrm{mg}$ GAE/g which was 2.6 times higher than the rest 4 red goji berry samples. Average TPC in these 4 red goji berries was recorded as $3.16 \mathrm{mg} \mathrm{GAE} / \mathrm{g}$, which differed significantly $(p<.05)$ from black goji berry. This finding indicates that the goji berry species are a significant source of phenolics.

The highest content of flavonoids was recorded as $12.32 \mathrm{mg} \mathrm{CAE} / \mathrm{g}$, while the least flavonoids were recorded as $2.67 \mathrm{mg} \mathrm{CAE} / \mathrm{g}$. The average TFC value was recorded as $11.09 \mathrm{mg} \mathrm{CAE} / \mathrm{g}$ from 4 black goji berry samples, which was 3.9 times higher than the 4 red goji berry samples, the average TFC value of 4 red goji berry samples was $2.83 \mathrm{mg} \mathrm{CAE} / \mathrm{g}$, which differed significantly $(p<.05)$ from the 4 black goji berry samples.

The highest condensed tannin content was recorded as $23.51 \mathrm{mg} \mathrm{CAE} / \mathrm{g}$ in black goji berry, while the least condensed tannin content was recorded as $.86 \mathrm{mg} \mathrm{CAE} / \mathrm{g}$ in red goji berry. The tannin content of black goji berry samples $20.87 \mathrm{mg} \mathrm{CAE} / \mathrm{g}$, was 19.3 times higher than the 4 red goji berry samples, the average condensed tannin content of 4 red goji berry sample was $1.08 \mathrm{mg} \mathrm{CAE} / \mathrm{g}$, which differed significantly $(p<.05)$ from the 4 black goji berry samples.

The highest monomeric anthocyanin content was recorded as $82.58 \mathrm{mg} \mathrm{MAC/g}$ from black goji berry, while the least condensed tannin content was recorded as $.21 \mathrm{mg} \mathrm{MAC/g}$ from red goji berry. The average monomeric anthocyanin content was recorded $72.86 \mathrm{mg} \mathrm{MAC/g}$ from 4 black goji berry samples, which 
was 30.4 times higher than the 4 red goji berry samples, the average monomeric anthocyanin content of 4 red goji berry samples was $.24 \mathrm{mg} \mathrm{MAC/g}$, which differed significantly $(p<.05)$ from the 4 black goji berry samples.

\section{Antioxidant capacities of goji berry}

The highest scavenging activity of goji berry extract was recorded as $35.86 \mu \mathrm{mol} \mathrm{TE} / \mathrm{g}$, while the least $\mathrm{DPPH}$ scavenging activity was recorded as $16.07 \mu \mathrm{mol} \mathrm{TE} / \mathrm{g}$. The average value of 4 black goji berry samples was $34.28 \mu \mathrm{mol} \mathrm{TE} / \mathrm{g}$, which was 2 times higher than 4 red goji berries. The average value of 4 red goji berries was $16.65 \mu \mathrm{mol} \mathrm{TE} / \mathrm{g}$.

Table 3 presents the reducing capability of 8 goji berry samples, the highest FRAP value was recorded as $36,346.61 \mathrm{mmol} \mathrm{Fe} e^{2+} \mathrm{E} / 100 \mathrm{~g}$, and the lowest FRAP value was $2639.03 \mathrm{Fe}^{2+} \mathrm{E} / 100 \mathrm{~g}$. The principle of FRAP assay states that, with reductant (antioxidants) at low $\mathrm{pH}$, ferric tripyridyltriazine (Fe(III)-TPTZ) is reduced to ferrous tripyridyltriazine (Fe(II)-TPTZ) that has an intensive blue color and can be detected at a wavelength of $593 \mathrm{~nm}$ [23].

The highest ABTS radical scavenging activity was recorded as $180.03 \mu \mathrm{mol} \mathrm{TE} / \mathrm{g}$ from black goji berry, while the lowest ABTS radical scavenging activity was recorded as $53.92 \mu \mathrm{mol} \mathrm{TE} / \mathrm{g}$. The average of 4 black goji berries was $161.28 \mu \mathrm{mol} \mathrm{TE} / \mathrm{g}$, while the lowest value was $59.14 \mu \mathrm{mol} \mathrm{TE} / \mathrm{g}$ from 4 red goji berry samples. The ABTS radical scavenging activity is a more sensitive radical that is used for the estimation of antioxidant activity. The reduced ABTS radical is colorless in a color-quenching reaction [36].

\section{Carotenoid content in goji berry}

The total carotenoid contents (TCC) of goji berries are shown in Table 4. The highest carotenoid was $233.08 \mu \mathrm{g} / \mathrm{g}$ from red goji berry, while the lowest value was recorded as $1.51 \mu \mathrm{g} / \mathrm{g}$ from black goji berry. The average value of 4 red goji berries was $223.04 \mu \mathrm{g} / \mathrm{g}$, while the average value of 4 black goji berries was $2.36 \mu \mathrm{g} / \mathrm{g}$. The current results are similar as a previous study by Liu et al. [37], in which red goji berry was found to accumulate high levels (a maximum of $508.9 \mu \mathrm{g} / \mathrm{g}$ on fresh weight basis) of carotenoids, while the carotenoids were from $34.46 \mu \mathrm{g} / \mathrm{g}$ to undetectable in the black goji berry.

\section{Correlation between antioxidant capacities and phenolic compounds}

The correlation between antioxidant capacities and phenolics is shown in Table 5. The results of TPC, TFC, CTA, and MAC exhibited positive linear correlation at the level of .01 $(r=.5)$. The results of FRAP, DPPH, and ABTS exhibited a positive linear correlation at the level of .01 , where $r=.643$ for FRAP and DPPH, $r=.571$ for $\mathrm{DPPH}$ and ABTS, and $\mathrm{r}=.786$ for FRAP and ABTS. The correlation between phenolics and antioxidant capacities of 8 goji berry samples exhibited a positive linear correlation at the level of .01 , where $r=.857$ for TPC and FRAP, $\mathrm{r}=.786$ for TPC and DPPH, $\mathrm{r}=.643$ for TPC and ABTS, $\mathrm{r}=.786$ for TFC and FRAP, $\mathrm{r}=.875$ for TFC and DPPH, $\mathrm{r}=.714$ for TFC and ABTS, $\mathrm{r}=.857$ for MAC and FRAP, $r=.643$ for MAC and DPPH, $r=.786$ for MAC and ABTS, $r=.643$ for CTC and FRAP, $r=.429$ for CTC and $\mathrm{DPPH}, \mathrm{r}=.714$ for CTC and ABTS. Between carotenoid (TCC) and phenolics, carotenoid (TCC) and antioxidant capacities of 8 goji berries samples there is a negative correlation. The results dictate that phenolic compounds could be important contributors toward the antioxidant capacities of these goji berries. Phenolic compounds, such as flavonoids, phenolic acids, and condensed tannins, are usually considered to be major contributors to the antioxidant capacities of plants [38].

\section{Conclusions}

The 8 black and red goji samples have substantial antioxidant capacity and contain large amount of phenolic compounds. A significant correlation between the $\mathrm{DPPH}, \mathrm{FRAP}$ and ABTS values suggested that antioxidant assays are reliable. The highly positive correlation between antioxidant capacity, phenolic, flavonoid, condensed tannin and anthocyanin content indicated that phenolic compounds could be the main contributors to the antioxidant activities of these goji berries. The black goji berries have relatively higher antioxidant capacities, total phenolic, flavonoid, condensed tannin and anthocyanin, and it could be an important dietary source of natural antioxidants for the 
Table 5 Correlation analysis among the antioxidant, phenolics and carotenoids

\begin{tabular}{|c|c|c|c|c|c|c|c|c|}
\hline & TPC & TFC & FRAP & DPPH & ABTS & MAC & CTC & TCC \\
\hline \multicolumn{9}{|l|}{ TPC } \\
\hline Correlation coefficient & 1.000 & $.643^{\mathrm{a}}$ & $.857^{b}$ & $.786^{\mathrm{b}}$ & $.643^{\mathrm{a}}$ & $.714^{\mathrm{a}}$ & .500 & -.500 \\
\hline Sig. (2-tailed) & - & .026 & .003 & .006 & .026 & .013 & .083 & .083 \\
\hline $\mathrm{N}$ & 8 & 8 & 8 & 8 & 8 & 8 & 8 & 8 \\
\hline \multicolumn{9}{|l|}{ TFC } \\
\hline Correlation coefficient & $.643^{\mathrm{a}}$ & 1.000 & $.786^{\mathrm{b}}$ & $.857^{b}$ & $.714^{\mathrm{a}}$ & $.786^{\mathrm{b}}$ & $.571^{\mathrm{a}}$ & $-.571^{a}$ \\
\hline Sig. (2-tailed) & .026 & - & .006 & .003 & .013 & .006 & .048 & .048 \\
\hline $\mathrm{N}$ & 8 & 8 & 8 & 8 & 8 & 8 & 8 & 8 \\
\hline \multicolumn{9}{|l|}{ FRAP } \\
\hline Correlation coefficient & $.857^{\mathrm{b}}$ & $.786^{\mathrm{b}}$ & 1.000 & $.643^{\mathrm{a}}$ & $.786^{\mathrm{b}}$ & $.857^{b}$ & $.643^{\mathrm{a}}$ & -.357 \\
\hline Sig. (2-tailed) & .003 & .006 & - & .026 & .006 & .003 & .026 & .216 \\
\hline $\mathrm{N}$ & 8 & 8 & 8 & 8 & 8 & 8 & 8 & 8 \\
\hline \multicolumn{9}{|l|}{ DPPH } \\
\hline Correlation coefficient & $.786^{\mathrm{b}}$ & $.857^{\mathrm{b}}$ & $.643^{\mathrm{a}}$ & 1.000 & $.571^{\mathrm{a}}$ & $.643^{\mathrm{a}}$ & .429 & $-.714^{a}$ \\
\hline Sig. (2-tailed) & .006 & .003 & .026 & - & .048 & .026 & .138 & .013 \\
\hline $\mathrm{N}$ & 8 & 8 & 8 & 8 & 8 & 8 & 8 & 8 \\
\hline \multicolumn{9}{|l|}{ ABTS } \\
\hline Correlation coefficient & $.643^{\mathrm{a}}$ & $.714^{\mathrm{a}}$ & $.786^{\mathrm{b}}$ & $.571^{\mathrm{a}}$ & 1.000 & $.786^{\mathrm{b}}$ & $.714^{\mathrm{a}}$ & -.286 \\
\hline Sig. (2-tailed) & .026 & .013 & .006 & .048 & - & .006 & .013 & .322 \\
\hline N & 8 & 8 & 8 & 8 & 8 & 8 & 8 & 8 \\
\hline \multicolumn{9}{|l|}{ MAC } \\
\hline Correlation coefficient & $.714^{\mathrm{a}}$ & $.786^{\mathrm{b}}$ & $.857^{b}$ & $.643^{\mathrm{a}}$ & $.786^{\mathrm{b}}$ & 1.000 & $.786^{\mathrm{b}}$ & -.500 \\
\hline Sig. (2-tailed) & .013 & .006 & .003 & .026 & .006 & - & .006 & .083 \\
\hline $\mathrm{N}$ & 8 & 8 & 8 & 8 & 8 & 8 & 8 & 8 \\
\hline \multicolumn{9}{|l|}{ СTC } \\
\hline Correlation coefficient & .500 & $.571^{\mathrm{a}}$ & $.643^{\mathrm{a}}$ & .429 & $.714^{\mathrm{a}}$ & $.786^{\mathrm{b}}$ & 1.000 & -.429 \\
\hline Sig. (2-tailed) & .083 & .048 & .026 & .138 & .013 & .006 & - & .138 \\
\hline $\mathrm{N}$ & 8 & 8 & 8 & 8 & 8 & 8 & 8 & 8 \\
\hline \multicolumn{9}{|l|}{ TCC } \\
\hline Correlation coefficient & -.500 & $-.571^{\mathrm{a}}$ & -.357 & $-.714^{\mathrm{a}}$ & -.286 & -500 & -.429 & 1.000 \\
\hline Sig. (2-tailed) & .083 & .048 & .216 & .013 & .322 & .083 & .138 & - \\
\hline $\mathrm{N}$ & 8 & 8 & 8 & 8 & 8 & 8 & 8 & 8 \\
\hline
\end{tabular}

a Correlation is significant at the .05 level (2-tailed)

b Correlation is significant at the .01 level (2-tailed)

prevention of diseases caused by oxidative stress in human body. This study portrayed an in depth detail on the antioxidant functions of goji berry which is of significant importance to consumers, nutritionists and food researchers.

\section{Authors' contributions}

TI conducted lab work, data processing, statistical analysis and manuscript drafting. XY collected all experimental samples and conducted parts of lab work. TSB was involved in the sample preparation and conducted parts of lab work. BX made experimental design, conducted quality control for lab work, and took charge in manuscript revision and paper submission. All authors read and approved the final manuscript.

\section{Author details}

1 Food Science and Technology Program, Beijing Normal University-Hong Kong Baptist University United International College, 28, Jinfeng Road, Tangjiawan, Zhuhai 519085, Guangdong, China. ${ }^{2}$ Agricultural and Food Engineering
Department, Indian Institute of Technology, Kharagpur, West Bengal 721302, India.

\section{Acknowledgements}

This research was jointly supported by two research grants (UIC R201624 and UIC R201714) from Beijing Normal University-Hong Kong Baptist University United International College, China.

\section{Competing interests}

The authors declare that they have no competing interests.

\section{Publisher's Note}

Springer Nature remains neutral with regard to jurisdictional claims in published maps and institutional affiliations.

Received: 18 November 2016 Accepted: 15 June 2017 Published online: 24 June 2017 


\section{References}

1. Orhan I, Üstün O (2011) Determination of total phenol content, antioxidant activity and acetylcholinesterase inhibition in selected mushrooms from Turkey. J Food Compos Anal 24(3):386-390

2. Gu L, Weng X (2001) Antioxidant activity and components of Salvia plebeia R. Br.-a Chinese herb. Food Chem 73(3):299-305

3. Yildirim NC, Turkoglu S, Yildirim NUMAN, Ince OK (2012) Antioxidant properties of wild edible mushroom Pleurotus eryngii collected from Tunceli province of Turkey. Digest J Nanomater Biostruct 7:1647-1654

4. Cosio MS, Buratti S, Mannino S, Benedetti S (2006) Use of an electrochemical method to evaluate the antioxidant activity of herb extracts from the Labiatae family. Food Chem 97(4):725-731

5. Ferreira IC, Barros L, Abreu R (2009) Antioxidants in wild mushrooms. Curr Med Chem 16(12):1543-1560

6. Jung K, Chin YW, Kim YC, Kim J (2005) Potentially hepatoprotective glycolipid constituents of Lycium chinense fruits. Arch Pharmacal Res 28(12):1381-1385

7. Kocyigit E, Sanlier N (2017) A review of composition and health effects of Lycium barbarum. Int J Chin Med 1(1):1-9

8. Li XM, Ma YL, Liu XJ (2007) Effect of the Lycium barbarum polysaccharides on age-related oxidative stress in aged mice. J Ethnopharmacol 111(3):504-511

9. Li W, Wang L, Deng X, Jiang L, Zhang C, Zhang C (2000) Study of the fragility and abnormality rate of red blood cells in patients with type- 2 diabetes and the effects of Lycium barbarum polysaccharides. Hebei $J$ Tradit Chin Med 22(8):585-586

10. Fraser PD, Bramley PM (2004) The biosynthesis and nutritional uses of carotenoids. Prog Lipid Res 43:228-265

11. Luo Q, Cai Y, Yan J, Sun M, Corke H (2004) Hypoglycemic and hypolipidemic effects and antioxidant activity of fruit extracts from Lycium barbaru. Life Sci 76:137-149

12. Weller P, Breithaupt $E$ (2003) Identification and quantification of zeaxanthin esters in plants using liquid chromatography-mass spectrometry. Agric Food Chem 51:7044-7049

13. Amagase $H$, Farnsworth NR (2011) A review of botanical characteristics, phytochemistry, clinical relevance in efficacy and safety of Lycium barbarum fruit (goji). Food Res Int 44:1702-1717

14. Potterat O (2010) Goji (Lycium barbarum and L. chinense): phytochemistry, pharmacology and safety in the perspective of traditional uses and recent popularity. Planta Med 76:7-19

15. Jin ML, Huang QS, Zhao K, Shang P (2013) Biological activities and potential health benefit effects of polysaccharides isolated from Lycium barbarum L. Int J Biol Macromol 54:16-23

16. Yu MS, Leung SK, Lai SW, Che CM, Zee SY, So KF, Yuen WH, Chang RCC (2005) Neuroprotective effects of anti-agingoriental medicine Lycium barbarum against beta-amyloid peptide neurotoxicity. Exp Gerontol 40(8-9):716-727

17. Peng Q, Lv XP, Xu QS, Li Y, Huang LJ, Du YG (2012) Isolation and structural characterization of the polysaccharide LRGP1 from Lycium ruthenicum. Carbohydr Polym 90:95-101

18. Zheng J, Ding CX, Wang LS, Li GL, Shi JY, Li H, Wang HL, Suo YR (2011) Anthocyanins composition and antioxidant activity of wild Lycium ruthenicum Murr. from Qinghai-Tibet Plateau. Food Chem 126:859-865

19. Breithaupt DE, Weller P, Wolters M, Hahn A (2004) Comparison of plasma responses in human subjects after the ingestion of $3 R, 3 R^{\prime}$-zeaxanthin dipalmitate from wolfberry (Lycium barbarum) and non-esterified $3 R, 3 R^{\prime}$ zeaxanthin using chiral high-performance liquid chromatography. $\mathrm{Br} J$ Nutr 91(5):707-713

20. Chang RC, So KF (2008) Use of anti-aging herbal medicine, Lycium barbarum, against aging-associated diseases. What do we know so far? Cell Mol Neurobiol 28(5):643-652

21. Peng X, Tian G (2001) Structural characterization of the glycan part of glycoconjugate LbGp2 from Lycium barbarum L. Carbohydr Res 331 (1):95-99

22. Zhao R, Li Q, Xiao B (2005) Effect of Lycium barbarum polysaccharide on the improvement of insulin resistance in NIDDM rats. Yakugaku Zasshi 125(12):981-988
23. Xu BJ, Chang SKC (2007) A comparative study on phenolic profiles and antioxidant activities of legumes as affected by extraction solvents. J Food Sci 72:159-166

24. Singleton VL, Lamuela-Raventos RM (1999) Analysis of total phenols and other oxidation substrates and antioxidants by means of Folin-Ciocalteu reagent. Methods Enzymol 299:152-178

25. Singleton VL, Rossi JA (1965) Colorimetry of total phenolic with phosphomolybdic-phosphotungstic acid reagents. Am J Enol Vitic 16:144-158

26. Heimler D, Vignolini P, Dini MG, Romani A (2005) Rapid tests to assess the antioxidant activity of Phaseolus vulgaris L. dry beans. J Agric Food Chem 53:3053-3056

27. Broadhurst RB, Jones WT (1978) Analysis of condensed tannins using acidified vanillin. J Sci Food Agric 29:788-794

28. Lee J, Durst RW, Wrolstad RE (2005) Determination of total monomeric anthocyanin pigment content of fruit juices, beverages, natural colorants, and wines by the $\mathrm{pH}$ differential method: collaborative study. J AOAC Int 88:1269-1278

29. Chen CW, Ho CT (1995) Antioxidant properties of polyphenols extracted from green and black teas. J Food Lipids 2:35-46

30. Benzie IF, Strain JJ (1996) The ferric reducing ability of plasma (FRAP) as a measure of "antioxidant power": the FRAP assay. Anal Biochem 239(1):70-76

31. Brown JM, Miller WR (1993) Impact of motivational interviewing on participation and outcome in residential alcoholism treatment. Psychol Addict Behav 7(4):211

32. Re R, Pellegrini N, Proteggente A, Pannala A, Yang M, Rice-Evans C (1999) Antioxidant activity applying an improved ABTS radical cation decolorization assay. Free Radic Biol Med 26(9):1231-1237

33. Sanusi RA, Adebiyi AE (2009) Beta carotene content of commonly consumed foods and soups in Nigeria, Pakistan. J Nutr 8:1512-1516

34. Carvalho LM, Oliveira AR, Godoy RL, Pacheco S, Nutti MR, de Carvalho JL, Fukuda WG (2012) Retention of total carotenoid and $\beta$-carotene in yellow sweet cassava (Manihot esculenta Crantz) after domestic cooking. Food Nutr Res 56:15788

35. Song Y, Xu BJ (2013) Diffusion profiles of health beneficial components from goji berry (Lyceum barbarum) marinated in alcohol and their antioxidant capacities as affected by alcohol concentration and steeping time. Foods 2:32-42

36. Elekofehinti OO, Kamdem JP, Kade IJ, Adanlawo IG, Rocha JBT (2013) Saponins from Solanum anguivilam fruit exhibit in vitro and in vivo antioxidant activity in alloxan induced oxidative stress. Asian J Pharm Clin Res 6:249-254

37. Liu Y, Zeng S, Sun W, Wu M, Hu W, Shen X, Wang Y (2014) Comparative analysis of carotenoid accumulation in two goji (Lycium barbarum L. and L. ruthenicum Murr.) fruits. BMC Plant Biol 14:269

38. Cai YZ, Luo Q, Sun M, Corke H (2004) Antioxidant activity and phenolic compounds of 112 traditional Chinese medicinal plants associated with anticancer. J Life Sci 74:2157-2184

\section{Submit your manuscript to a SpringerOpen ${ }^{\odot}$ journal and benefit from:}

- Convenient online submission

- Rigorous peer review

- Open access: articles freely available online

- High visibility within the field

- Retaining the copyright to your article

Submit your next manuscript at $>$ springeropen.com 